\title{
openheart Risk factors and therapeutic coverage at 6 years in patients with previous myocardial infarction: the CASTUO study
}

Francisco Javier Félix-Redondo, ${ }^{1}$ Luis Lozano Mera, ${ }^{2}$ Luciano Consuegra-Sánchez, ${ }^{3}$ Fernando Giménez Sáez, ${ }^{4}$ Francisco Javier Garcipérez de Vargas, ${ }^{4}$ José María Castellano Vázquez, ${ }^{5,6}$ Daniel Fernández-Bergés ${ }^{7}$

To cite: Félix-Redondo FJ, Lozano Mera L, ConsuegraSánchez L, et al. Risk factors and therapeutic coverage at 6 years in patients with previous myocardial infarction: the CASTUO study. Open Heart 2016;3:e000368. doi:10.1136/openhrt-2015000368

- Additional material is available. To view please visit the journal (http://dx.doi.org/ 10.1136/openhrt-2015000368).

Received 20 November 2015 Revised 30 January 2016 Accepted 2 February 2016

CrossMark

For numbered affiliations see end of article.

Correspondence to Dr Francisco Javier FélixRedondo;

felixredondofj@gmail.com

\section{ABSTRACT}

Objectives: To determine the degree of risk factor control, the clinical symptoms and the therapeutic management of patients with a history of previous myocardial infarction.

Methods: Cross-sectional study at 6 years of a first episode of acute myocardial infarction between 2000 and 2009, admitted at a hospital in the region of Extremadura (Spain). Of 2177 patients with this diagnosis, 1365 remained alive and therefore were included in the study.

Results: We conducted a person-to-person survey in $666(48.8 \%)$ individuals and telephone survey in 437 $(31.9 \%)$ individuals. The former are analysed. 130 were female $(19.5 \%)$. The mean age was 67.4 years and the median time since the event was 5.8 (IQR 3.68.2) years. Active smokers made up $13.8 \%$, lowdensity lipoprotein (LDL) cholesterol was $\geq 70 \mathrm{mg} / \mathrm{dL}$ : $82 \%$, blood pressure $\geq 140 / 90 \mathrm{~mm} \mathrm{Hg}(\geq 140 / 85$ in diabetics): $49.8 \%$, fasting glucose $\geq 126 \mathrm{mg} / \mathrm{dL}: 26 \%$, heart rate $50-59 \mathrm{bpm}: 60.7 \%$, and obesity: $45.9 \%$. Patients reported presenting angina comprised $22.4 \%$ and those with dyspnoea, $29.3 \%$. Drug coverage was: $88.0 \%$ antiplatelet drugs, $86.5 \%$ statins, $75.6 \% \beta$ blockers and $65.8 \%$ blockers of the renin-angiotensin system. Patients receiving all four types of drugs made up $41.9 \%$, with only $3.0 \%$ having jointly controlled cholesterol, blood pressure, heart rate and glycaemia. Conclusions: LDL cholesterol, heart rate and blood pressure were risk factors with less control. More than $1 / 5$ of patients had angina and more than 1/4, dyspnoea. Risk factor control and the clinical condition were far from optimal, as was drug coverage, although to a lesser degree.

\section{INTRODUCTION}

Patients with coronary heart disease represent a clinical priority for prevention due to the high risk of recurrence and the existence of effective drugs to prevent it. ${ }^{1}$ The European Society of Cardiology (ESG) supports a programme to periodically assess these patients.

\section{KEY QUESTIONS}

What is already known about this subject?

- Patients in secondary prevention after a myocardial infarction are still at high risk of recurrence and mortality in spite of good therapeutic coverage regarding the current recommendations of clinical practice guidelines. Recent European studies showed a lack of control of cardiovascular risk factors. Most of the available information comes from patients recruited from university tertiary hospitals and large cardiology centres, and the follow-up is relatively short.

What does this study add?

- This study provides information about the degree of control regarding risk factors and therapeutic coverage at 6 years in patients with a previous myocardial infarction admitted to a general hospital. Our results are very similar to those obtained in other European studies. Further, in our study, the condition of diabetes and a low estimated glomerular filtration rate were the two main important variables associated with worse control of cardiovascular risk factors.

How might this impact on clinical practice?

- Importantly, we show that the difficulties in obtaining control of risk factors in patients with myocardial infarction appear to be independent of the care setting and the time from the coronary event. We should make an effort to identify and more aggressively treat those patients with diabetes and a low estimated glomerular filtration rate.

The latest ESC report ${ }^{2}$ highlights the persistence of poor blood pressure and low-density lipoprotein cholesterol (LDL-C) control, a high prevalence of tobacco use and even a worsening of the obesity rate, compared to the previous reports. This is in spite of the good treatment coverage with drugs recommended in the clinical practice guidelines. ${ }^{1}$ 
Spanish data from several registries ${ }^{3-7}$ are consistent with those mentioned above, and continued improvement of treatment coverage at discharge and risk factor control in the stable disease phase has been reported. ${ }^{8}$

On the other hand, gender ${ }^{7}$ and age-related ${ }^{70}$ differences with regard to the diagnosis and treatment in the acute phase of the disease have been reported. Several authors have been calling attention to the importance of the apparent disparity in care. ${ }^{11} 12$ This is of special interest for Spain because there are estimates that the population most likely to suffer acute coronary syndromes are females and the elderly (over 75 years of age) ${ }^{13}$ We do not know if these differences in care may also be occurring in the stable phase of the disease.

To date, the main study conducted in Spain on managing stable coronary heart disease ${ }^{8}$ included a sample recruited exclusively in cardiology departments and a short time to evaluation after the coronary event. There is poor or no information regarding regional hospitals, which are distinguished by a lower use of diagnostic and therapeutic interventions during admission. ${ }^{7}$

We aimed to determine the degree of risk factor control, clinical condition and therapeutic management of patients who suffered an acute myocardial infarction (AMI) between 2000 and 2009, and who were discharged from a regional hospital in the northwest of Badajoz province (Extremadura, Spain).

\section{METHODS}

\section{Design and study population}

This is a cross-sectional study of those patients who survived a first AMI, between 2000 and 2009, requiring admission to a regional hospital, Don Benito-Villanueva de la Serena. Of 2177 subjects who were admitted due to AMI, $1365(62.5 \%)$ were alive during the study recruitment period, January to September 2011, of whom $666(48.8 \%)$ agreed to participate in the person-to-person interview. Of the remaining 699, 437 were interviewed by telephone $(62.5 \%)$. The most common reasons for not participating were logistical transportation difficulties $(76.7 \%)$, living outside the health area or the community $(26.3 \%)$ and being institutionalised in nursing homes or lacking autonomy in mobility $(18.5 \%)$.

\section{Measurements}

Sociodemographic, clinical and treatment data since the hospital discharge report were collected for all subjects alive at the time of the study. For those who agreed to a personal interview, information was collected about comorbidity, risk factors, clinical condition regarding the presence of angina symptoms or dyspnoea and current drug treatment. Several anthropometric, blood pressure and 12-lead electrocardiogram tests were performed, and baseline blood and urine samples taken. A proportion of patients completed a telephone survey about clinical and treatment information.
Weight and height were measured in indoor clothing, without shoes. Waist circumference was measured with a tape measure at the midway point between the lowest rim of the rib cage and the superior iliac crest. Fasting blood pressure was measured, after 5 min of rest, using a programmable electronic OMRON HEM 907 device and a suitably sized arm band. Three measurements were taken in the dominant arm, with a 1 min pause between them. The mean of the second and third measurement was selected as the representative figure for each individual.

Venous blood was drawn after a $10 \mathrm{~h}$ fast, after a night's sleep. The samples were processed at the place of extraction and were transported under standard conditions to the reference laboratory. A first morning urine sample was collected to analyse urinary albumin excretion corrected by creatinine.

\section{Variables}

Sociodemographic, clinical and treatment variables were selected at discharge and at the time of the survey, to characterise the sample and compare it with the nonparticipants. The variables of interest for the main analysis were persistent active tobacco use after the infarction, presenting blood pressure under $140 / 90 \mathrm{~mm} \mathrm{Hg}$ in general and under 140/85 in patients with diabetes, having LDL-C under $70 \mathrm{mg} / \mathrm{dL}$, heart rate less than $60 \mathrm{bpm}$ and greater than $49 \mathrm{bpm}$, body mass index under 30, and abdominal circumference under $102 \mathrm{~cm}$ in men and $88 \mathrm{~cm}$ in women. The grouped analysis of LDL-C, blood pressure, heart rate and blood glucose was also considered to assess patients with better control.

The optimal medical therapy (OMT) was considered as receiving antiplatelet drugs (anticoagulants if indicated), statins, $\beta$-blockers and an ACE inhibitor or angiotensin II receptor blocker (ARB).

Other variables analysed for their prognostic interest were the presence of kidney failure, through an estimated glomerular filtration rate according to the MDRD-IDMS formula under $60 \mathrm{~mL} / \mathrm{min}$, albuminuria through an albumin/creatinine ratio in morning urine greater than $30 \mathrm{mg} / \mathrm{g},{ }^{14}$ the prevalence of patients with high-density lipoprotein cholesterol under 40 and $45 \mathrm{mg} / \mathrm{dL}$, in men and women, respectively, or plasma triglycerides $>150 \mathrm{mg} / \mathrm{dL}$. In addition, the drug treatment was assessed for cases of angina, dyspnoea and atrial fibrillation.

\section{Analysis}

Continuous variables are expressed as the mean and SD or median and IQR, depending on the normality of distribution. Qualitative variables are expressed as absolute and relative frequencies. Differences between continuous variables were analysed using Student $t$ test or the Mann-Whitney U test. Differences between qualitative variables were analysed using the $\chi^{2}$ test or Fisher's test as appropriate. To determine those factors associated with the dependent variable, a multiple binary logistic 
regression analysis was performed. The dependent variable was considered as having at least two of the following risk factors outside the control range: LDL-C, blood pressure, blood glucose and heart rate. The independent variables tested were those that have been shown to influence control over these risk factors according to the literature, and in the bivariate analysis, where correlation with the dependent variable showed a significance level less than 0.10 . The variable selection method used was enter. SPSS V.20 (IBM, USA) was used in the present study.

\section{RESULTS}

\section{Characteristics of the participants}

In table 1, the demographic, clinical and treatment data are compared between the individuals who participated in the person-to-person survey and those who did not, at the time of hospital discharge. The participants were younger, with fewer women, less comorbidity, more coronary angiography and angioplasty performed, and more prescriptions for $\beta$-blockers and statins. Clinical and treatment data were also compared between participants in the person-to-person interview and those who completed the telephone survey (see online supplementary table $\mathrm{S} 1$ ).

The mean age (SD) of the participants at the time of the interview was 67.4 (12.0) years, ranging between 37 and 95 years. Women were on average 7.3 years $(95 \% \mathrm{CI}$ 5.2 to 9.4 ) older than men. The median time (IQR) between the coronary event and the interview was 5.8 (3.6-8.2) years, with no gender difference (table 2).

Table 2 shows sociodemographic, clinical and treatment data by gender. Of note, there is a substantial persistence of tobacco use in men, higher prevalence of diabetes and hypertension in women, and low, comparable comorbidity in both sexes. Women received fewer coronary angiographies and angioplasties. With regard to functional status, nearly one in four patients reported having angina, $66.4 \%$ of them needed sublingual nitroglycerine to relieve it, 30\% mentioned having some degree of physical limitation due to dyspnoea, with women being more frequently limited, and $10 \%$ experienced both clinical conditions. Women also had a higher prevalence of chronic kidney disease and atrial fibrillation. The treatment prescription was similar in both sexes, except for a higher indication for diuretics in women.

\section{Risk factor control and optimal medical therapy}

The degree of control over the main risk factors by gender is presented in figure 1 . Notably, we observed a high prevalence of abdominal obesity in women, and uncontrolled LDL-C, heart rate and blood pressure in men and women.

Figure 2 shows the proportion of subjects within the control range of the risk factors according to prescriptions of specific drugs. For blood pressure, the degree of control was no different according to the number of antihypertensive drugs indicated, with $55.1 \%, 49.0 \%$, $43.1 \%$ and $55.3 \%$ for $1,2,3$ and 4 or more drugs, respectively ( $\mathrm{p}$ value for trend: 0.056 ). The number of individuals with all four risk factors within the control range was $20(3.0 \%)$, none of them women, and 169 (25.4\%) for at least three factors, (16.9\% women, $27.4 \%$ men, $\mathrm{p}=0.014)$. Of those patients with known diabetes, $173(75.2 \%)$ received drugs: $148(64.3 \%)$ received oral antidiabetics and $55(23.9 \%)$ received insulin.

Two hundred and seventy-eight $(41.9 \%)$ individuals received the OMT, reaching $296(44.4 \%)$ if we include those who received anticoagulants, with no differences by gender in both cases. These individuals had better LDL-C $(21.6 \%$ vs $15.1 \%, \mathrm{p}=0.030)$ and heart rate $(46.3 \%$ vs $33.8 \%, \mathrm{p}=0.001)$ control, but not better blood pressure control (46.6\% vs $53 \%, \mathrm{p}=0.103)$.

\section{Treatment indication by clinical condition}

Figures 3-5 demonstrate the treatment profile of patients with symptomatic angina, some degree of dyspnoea (functional classification II-IV) and atrial fibrillation, respectively. There were few differences with regard to medication between patients with angina versus those without (figure 3). Those with dyspnoea were more likely to be taking ACE inhibitors/ARBs, diuretics, aldosterone blockers, transdermal nitroglycerine and digoxin, however, they received fewer $\beta$-blockers (figure 4 ). The presence of atrial fibrillation (figure 5) was associated with greater use of anticoagulants instead of antiplatelet drugs. Two patients $(4.3 \%)$ did not receive either, and 4 $(8.7 \%)$ received both. Other differences in atrial fibrillation were greater use of ACE inhibitors/ARBs, aldosterone blockers, digoxin and transdermal nitroglycerine.

\section{Patient profile with worse risk factor control}

Four hundred and ninety-seven patients $(74.6 \%)$ did not have at least three of the four risk factors considered controlled. In the multivariate analysis, they were independently correlated with having a history of diabetes and an estimated glomerular filtration rate below $60 \mathrm{~mL} / \mathrm{min}$, adjusted by age, obesity and treatment with statins and $\beta$-blockers (table 3 ).

\section{DISCUSSION}

The main finding of our study is that the control of risk factors and medical treatment in patients 6 years after an AMI is far from optimal. Through this study, we show the reality, unknown until now, about the degree of risk factor control, the symptomology associated with coronary heart disease and drug coverage in patients treated at a regional hospital.

\section{Risk factor control}

The worst controlled risk factor was LDL-C, only $18 \%$ of patients reaching the control objective, similar to the results obtained in a recent European survey ${ }^{2}$ and 
Table 1 Demographic factors, medical history and medication at discharge between participants in person-to-person survey and non-participants

\begin{tabular}{|c|c|c|c|}
\hline Variables (\%) & $\begin{array}{l}\text { Person-to-person surve } \\
\text { Participants } \\
\text { N: } 666\end{array}$ & $\begin{array}{l}\text { Non-participants } \\
\text { N: } 699\end{array}$ & p Value \\
\hline Female & 19.5 & 33.9 & $<0.001$ \\
\hline Mean age (SD) & $62.0(12.2)$ & $71.2(11.8)$ & $<0.001$ \\
\hline \multicolumn{4}{|l|}{ Risk factors } \\
\hline Tobacco use & 36.6 & 22.6 & $<0.001$ \\
\hline HTN & 89.6 & 92.4 & 0.072 \\
\hline Hypercholesterolaemia & 75.7 & 61.5 & $<0.001$ \\
\hline Diabetes mellitus & 25.8 & 34.5 & $<0.001$ \\
\hline Subjective obesity & 14.9 & 15.7 & 0.655 \\
\hline \multicolumn{4}{|l|}{ Comorbidity } \\
\hline COPD/chronic asthma & 6.3 & 10.9 & 0.003 \\
\hline Stroke & 2.7 & 9.9 & $<0.001$ \\
\hline PAD & 1.5 & 3.1 & 0.082 \\
\hline Kidney failure & 2.0 & 5.9 & $<0.001$ \\
\hline Heart failure (admission) & 18.6 & 20.3 & 0.429 \\
\hline \multicolumn{4}{|c|}{ Diagnostic and revascularisation procedures } \\
\hline Coronary angiography & 60.5 & 33.5 & $<0.001$ \\
\hline $\mathrm{PCl}$ & 41.4 & 20 & $<0.001$ \\
\hline CABG & 2.7 & 2.7 & 0.986 \\
\hline \multicolumn{4}{|l|}{ Treatment } \\
\hline Antiplatelets & 94.3 & 91.4 & 0.040 \\
\hline Anticoagulants & 1.2 & 2.7 & 0.044 \\
\hline$\beta$-blockers & 77.8 & 67.2 & $<0.001$ \\
\hline ACE inhibitors & 42.6 & 44.9 & 0.396 \\
\hline ARB & 7.5 & 7.3 & 0.881 \\
\hline ACE Inhibitor or ARB & 50.2 & 52.2 & 0.445 \\
\hline Statins & 70.4 & 55.2 & $<0.001$ \\
\hline Fibrate & 0.9 & 0.3 & 0.137 \\
\hline Calcium channel blocker & 11.6 & 13.7 & 0.228 \\
\hline Diuretic & 16.5 & 32.3 & $<0.001$ \\
\hline Transdermal NTG & 10.7 & 27.2 & $<0.001$ \\
\hline Digoxin & 1.1 & 3.9 & 0.001 \\
\hline OAD & 9.5 & 11.9 & 0.149 \\
\hline Insulin & 5.9 & 7.6 & 0.203 \\
\hline
\end{tabular}

ARB, angiotensin II receptor blocker; COPD, chronic obstructive pulmonary disease; HTN, hypertension; NTG, nitroglycerine; OAD, oral antidiabetic; PAD, peripheral artery disease; PCI, percutaneous coronary intervention.

somewhat better than the $11.6 \%$ from the Spanish CODIMET survey. ${ }^{15}$ In our study, $87 \%$ of patients were treated with statins, above the percentage of the high income countries in the PURE study, ${ }^{16} 70.9 \%$, and below the Spanish and European date from the CLARIFY study ${ }^{8}$ (96\% and 93\%, respectively).

Heart rate is a prognostic factor ${ }^{17}$ rarely assessed in most studies. In our case, only $39.3 \%$ of patients were at optimal levels, while in the CLARIFY study, ${ }^{8}$ the mean was $65 \mathrm{bpm}$. In this regard, the most commonly used drugs were $\beta$-blockers in $75.6 \%$ of the cases, which increases the proportion of patients in the control range by $12.2 \%$. This coverage was between $45.6 \%$ in countries with high-income levels in the PURE study, ${ }^{16}$ and $73 \%$ and $83 \%$ in the European CLARIFY ${ }^{8}$ and EUROASPIRE $\mathrm{IV}^{2}$ studies, respectively, with the exception of elevated use of ivabradine in the CLARIFY study.
Blood pressure was well controlled in $50.6 \%$ of patients, a lower proportion in women $(38 \%$ vs $56 \%$, $\mathrm{p}=0.002$ ) and somewhat lower than those obtained in the EUROASPIRE IV study ${ }^{2}(56 \%$ and $58 \%$, for women and men, respectively). The control of this risk factor represents a challenge as shown by the fact that it has not improved with the various editions of the EUROASPIRE study ${ }^{18}$ and, in our case, we observed that it did not improve with increased use of antihypertensive drugs. When we analysed ACE inhibitor/ARB prescriptions, we found that it was prescribed to $2 / 3$ of patients, an intermediate level between the $51 \%$ in high income countries in the PURE study ${ }^{16}$ and the $75 \%$ found in the European surveys. ${ }^{28}$

Diabetes was a very common risk factor in our study, $34.5 \%$, similar to that found in the Spanish data from the CLARIFY study ${ }^{8}$ and higher than the European 
Table 2 Sociodemographic, clinical and therapeutic characteristics, in overall sample and by gender

\begin{tabular}{|c|c|c|c|c|}
\hline & $\begin{array}{l}\text { Total } \\
\text { N: } 666\end{array}$ & $\begin{array}{l}\text { Male } \\
\text { N: } 536(80.5 \%)\end{array}$ & $\begin{array}{l}\text { Female } \\
\text { N: } 130(19.5 \%)\end{array}$ & p Value \\
\hline Average age (SD) & $67.4(12.0)$ & $66.0(11.9)$ & $73.3(10.6)$ & $<0.001$ \\
\hline Median time since coronary event (IQR) & $5.8(3.5-8.2)$ & $5.8(3.5-8.2)$ & $5.5(3.8-8.1)$ & 0.625 \\
\hline \multicolumn{5}{|l|}{ Education } \\
\hline Illiterate/primary incomplete & $141(21.2)$ & $97(18.1)$ & $44(33.8)$ & \multirow[t]{3}{*}{$<0.001$} \\
\hline Completed primary & $435(65.4)$ & $357(66.7)$ & $78(60.0)$ & \\
\hline Secondary or higher & 89 (13.4) & $81(15.2)$ & $8(6.2)$ & \\
\hline \multicolumn{5}{|l|}{ Risk factors } \\
\hline Current smoker & $92(13.8)$ & 89 (16.6) & $3(2.3)$ & $<0.001$ \\
\hline Arterial hypertension & $585(88.8)$ & $464(87.4)$ & $121(95.5)$ & 0.021 \\
\hline Diabetes mellitus & $230(34.5)$ & $174(32.5)$ & $56(43.1)$ & 0.022 \\
\hline \multicolumn{5}{|l|}{ Comorbidity } \\
\hline Previous stroke & $41(6.2)$ & $24(4.5)$ & $17(13.2)$ & $<0.001$ \\
\hline Peripheral artery disease & $13(2.0)$ & $13(2.4)$ & 0 & 0.083 \\
\hline Chronic kidney disease & $28(4.2)$ & $20(3.7)$ & $8(6.2)$ & 0.217 \\
\hline COPD/asthma & $82(12.3)$ & 66 (12.3) & $16(12.4)$ & 0.978 \\
\hline \multicolumn{5}{|l|}{ Clinical condition } \\
\hline Angina & $149(22.4)$ & $113(21.1)$ & $36(27.9)$ & 0.095 \\
\hline Dyspnoea FC (II-IV) & $194(29.1)$ & $135(25.2)$ & $59(45.4)$ & $<0.001$ \\
\hline $\mathrm{FC} \mathrm{I}$ & 469 (70.5) & 399 (74.4) & $70(54.3)$ & $<0.001$ \\
\hline FC II & $174(26.2)$ & $121(22.6)$ & $53(41.1)$ & \\
\hline FC III & $16(2.4)$ & $13(2.4)$ & $3(2.3)$ & \\
\hline FC IV & $4(0.6)$ & $1(0.2)$ & $3(2.3)$ & \\
\hline Estimated GFR <60 mL/min & $115(17.3)$ & $75(14.0)$ & $40(30.8)$ & $<0.001$ \\
\hline Alb/Creat urine $>30$ mg/g & $111(16.8)$ & $83(15.6)$ & $28(22.0)$ & 0.080 \\
\hline Atrial fibrillation & 49 (7.4) & $33(6.2)$ & $16(12.3)$ & 0.016 \\
\hline Pacemaker rhythm & $14(2.1)$ & $12(2.2)$ & $2(1.5)$ & 0.618 \\
\hline LDL-C >100 mg/dL & $264(39.6)$ & $212(39.6)$ & $52(40.0)$ & 0.925 \\
\hline HDL-C $<40 \mathrm{M},<45 \mathrm{~W}$ & $153(23)$ & $126(23.5)$ & $27(20.8)$ & 0.506 \\
\hline $\mathrm{TGC}=>150$ & $172(25.8)$ & $138(25.7)$ & $34(26.2)$ & 0.924 \\
\hline \multicolumn{5}{|l|}{ Diagnostic and revascularisation procedure } \\
\hline Coronary angiography & $403(60.5)$ & $342(63.8)$ & $61(46.9)$ & 0.001 \\
\hline $\mathrm{PCl}$ & $276(41.4)$ & $239(44.6)$ & 37 (28.5) & 0.001 \\
\hline CABG & $18(2.7)$ & $14(2.6)$ & $4(3.1)$ & 0.769 \\
\hline \multicolumn{5}{|l|}{ Current medication } \\
\hline Antiplatelet & $586(88.0)$ & $475(88.8)$ & $111(86.0)$ & 0.386 \\
\hline Statins & $575(86.5)$ & 465 (86.9) & $110(84.6)$ & 0.492 \\
\hline$\beta$-blockers & $503(75.6)$ & $402(75.1)$ & $101(77.7)$ & 0.543 \\
\hline ACE inhibitors/ARB & $436(65.8)$ & $347(65.0)$ & 89 (69.0) & 0.389 \\
\hline Diuretic & $251(37.9)$ & $185(34.6)$ & 66 (51.2) & 0.001 \\
\hline Calcium channel blocker & $139(21.0)$ & $111(20.8)$ & $28(21.9)$ & 0.794 \\
\hline Transdermal NTG & 75 (11.3) & $58(10.9)$ & $17(13.3)$ & 0.442 \\
\hline Anticoagulant & $55(8.3)$ & $42(7.9)$ & $13(10.1)$ & 0.414 \\
\hline OAD & $148(22.2)$ & $114(21.3)$ & 34 (26.2) & 0.229 \\
\hline Insulin & 55 (8.3) & 39 (7.3) & $16(12.3)$ & 0.062 \\
\hline OAD or insulin & $173(26.0)$ & $132(24.6)$ & $41(31.5)$ & 0.107 \\
\hline
\end{tabular}

Alb/Creat, urine, ratio albuminuria/creatininuria; ARB, angiotensin II receptor blocker; CABG, coronary artery by-pass grafting; COPD, chronic obstructive pulmonary disease; FC, functional classification, classes I-IV according to the American Heart Association; GFR, estimated glomerular filtration rate according to MDRD-IDMS; HDL-C, high-density lipoprotein; LDL-C, low-density lipoprotein; NTG, nitroglycerine; OAD, oral antidiabetic; PCI, percutaneous coronary intervention; TGC, triglycerides.

mean of $25 \%$. Only $75.2 \%$ of known patients with diabetes were being treated with drugs, and less than one-third had their baseline blood glucose controlled, although the cardiovascular benefit of strict control of glycaemia in these patients is not clear. ${ }^{19}$ Active tobacco use after the coronary event was very rare in women $(2.3 \%)$, although most of them had never used it (data not shown). However, $16.6 \%$ of men continued smoking, somewhat fewer that the data from the EUROASPIRE IV study $(18 \%)^{2}$ and higher than the $9.4 \%$ from the Spanish data from the CLARIFY study. ${ }^{8}$ Our sample is characterised by the high prevalence of obesity, $45.3 \%$ of men and $48.5 \%$ of women, higher figures than those obtained in the European survey, ${ }^{2}$ which were $36 \%$ and $44 \%$, a proportion that has increased in recent editions. ${ }^{18}$ 


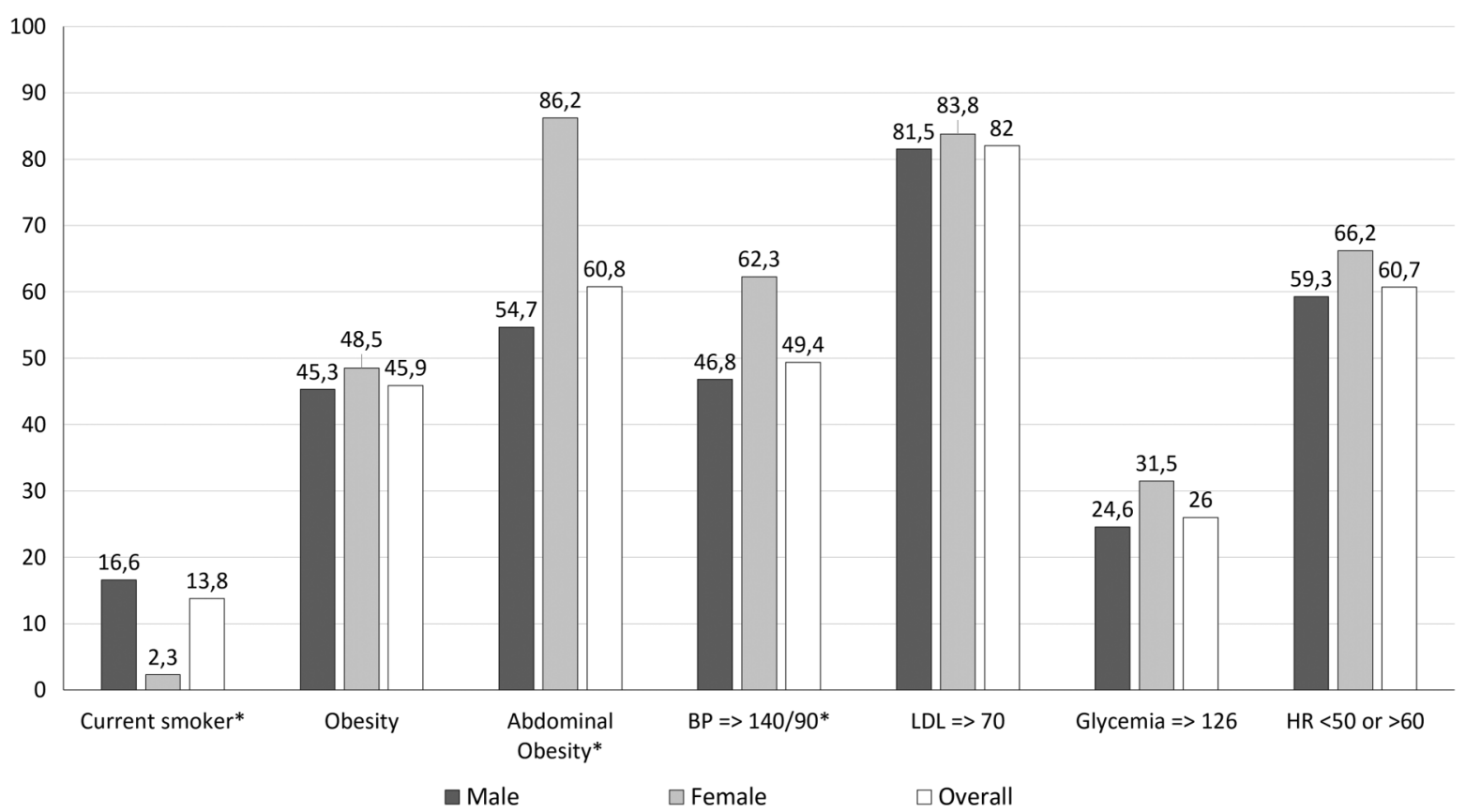

Figure 1 Level of risk factor control in the overall sample and by gender. *Prevalence differences between genders $(p<0.05)$. Blood pressure target in patients with diabetes was lower than $140 / 85 \mathrm{~mm} \mathrm{Hg}$. Abdominal obesity: waist circumference $\geq 102 \mathrm{~cm}$ in men, $\geq 88 \mathrm{~cm}$ in women, BP: blood pressure $(\mathrm{mm} \mathrm{Hg})$, Glycaemia: fasting plasma glucose $(\mathrm{mg} / \mathrm{dL})$, HR: heart rate (beats per minute), LDL: LDL cholesterol (mg/dL), obesity: BMI $\geq 30$.

\section{Clinical condition and drug treatment}

Overall, $41 \%$ of study patients had some functional limitation caused by angina or dyspnoea $(36.6 \%$ men, $59.2 \%$ women, $\mathrm{p}<0.001)$, clinical conditions that affect the patients' prognosis and quality of life. ${ }^{1}$ Angina prevalence in our study $(22.4 \%)$ was similar to that found in the Spanish CLARIFY data ${ }^{8}(21.8 \%)$, but much higher than the mean from European countries $(12.6 \%) .{ }^{8}$ However, its presence only induced a higher use of non-dihydropyridine calcium channel blockers.

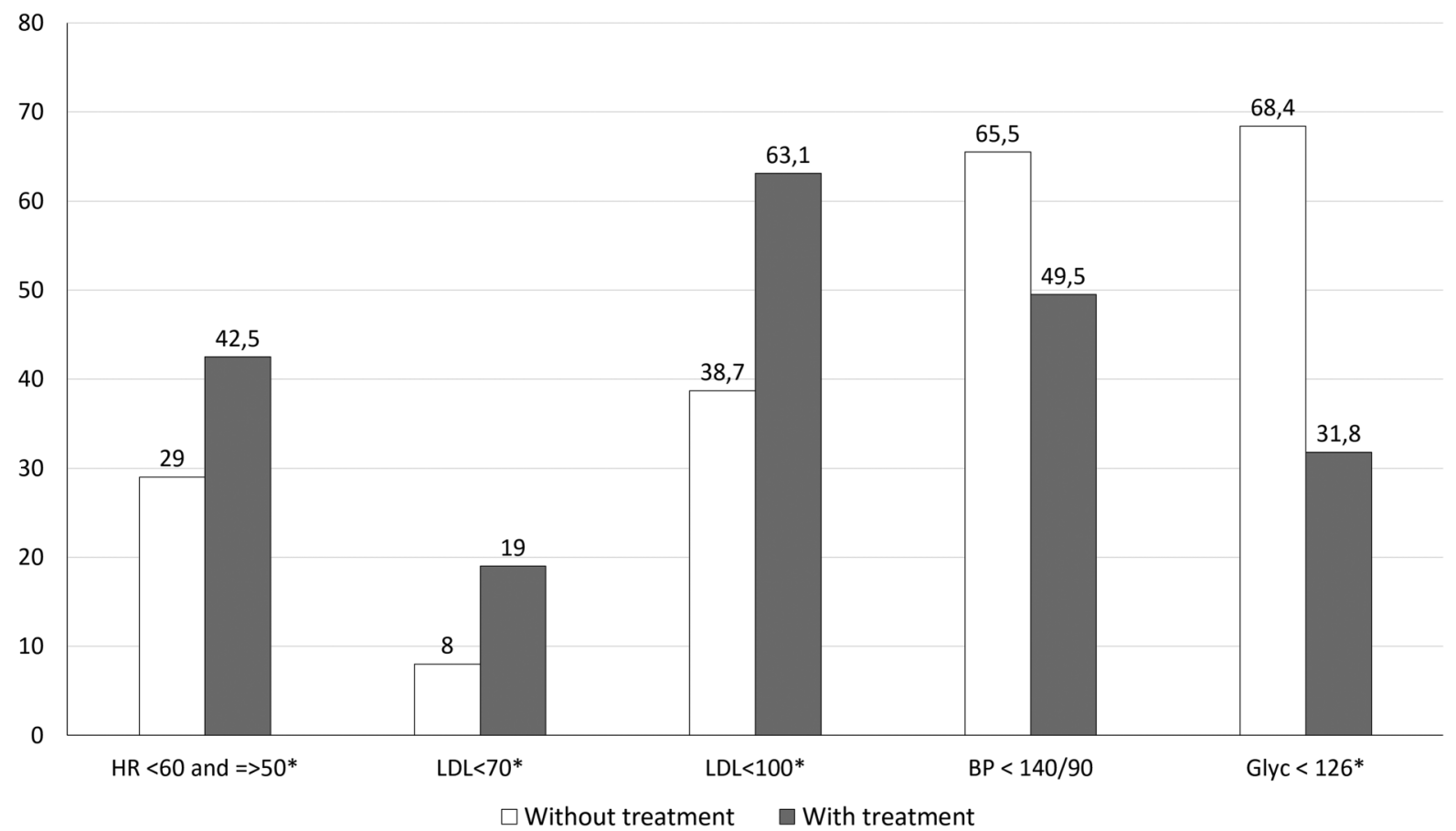

Figure 2 Prevalence (\%) in the control range for the various risk factors according to prescriptions of specific drugs. *Differences in prevalence $(p<0.05)$. Blood pressure target in patients with diabetes was lower than $140 / 85 \mathrm{~mm} \mathrm{Hg}$. BP, blood pressure (mm Hg); Glycaemia: fasting plasma glucose (mg/dL); HR, heart rate (beats per minute); LDL, LDL cholesterol (mg/dL). 


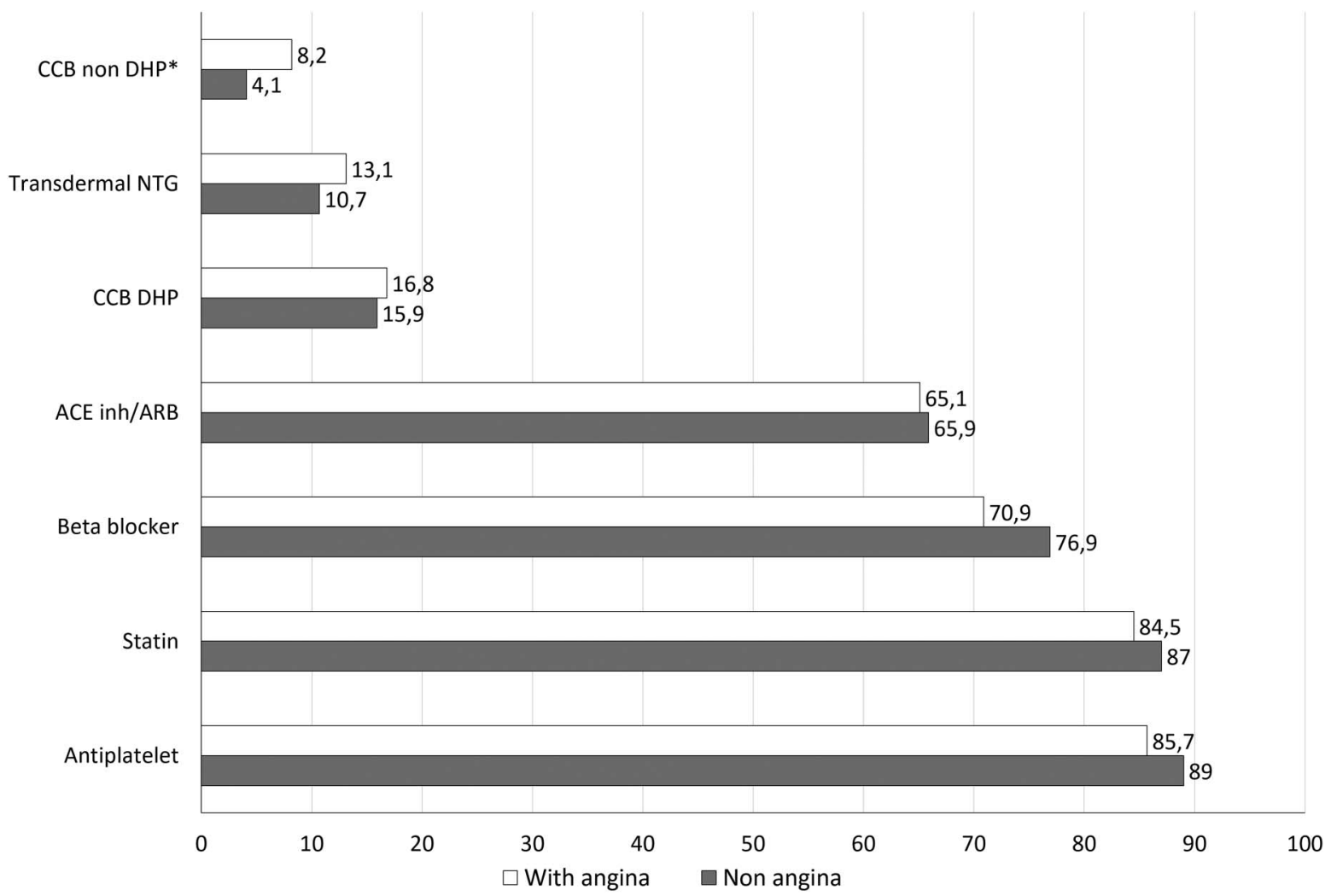

Figure 3 Treatment indication according to the presence of angina symptoms. *Prevalence differences $(p<0.05)$. ARB, angiotensin II receptor blocker; DHP/Non-DHP CCB, dihydropyridine/non-dihydropyridine calcium channel blockers; NTG, nitroglycerine.

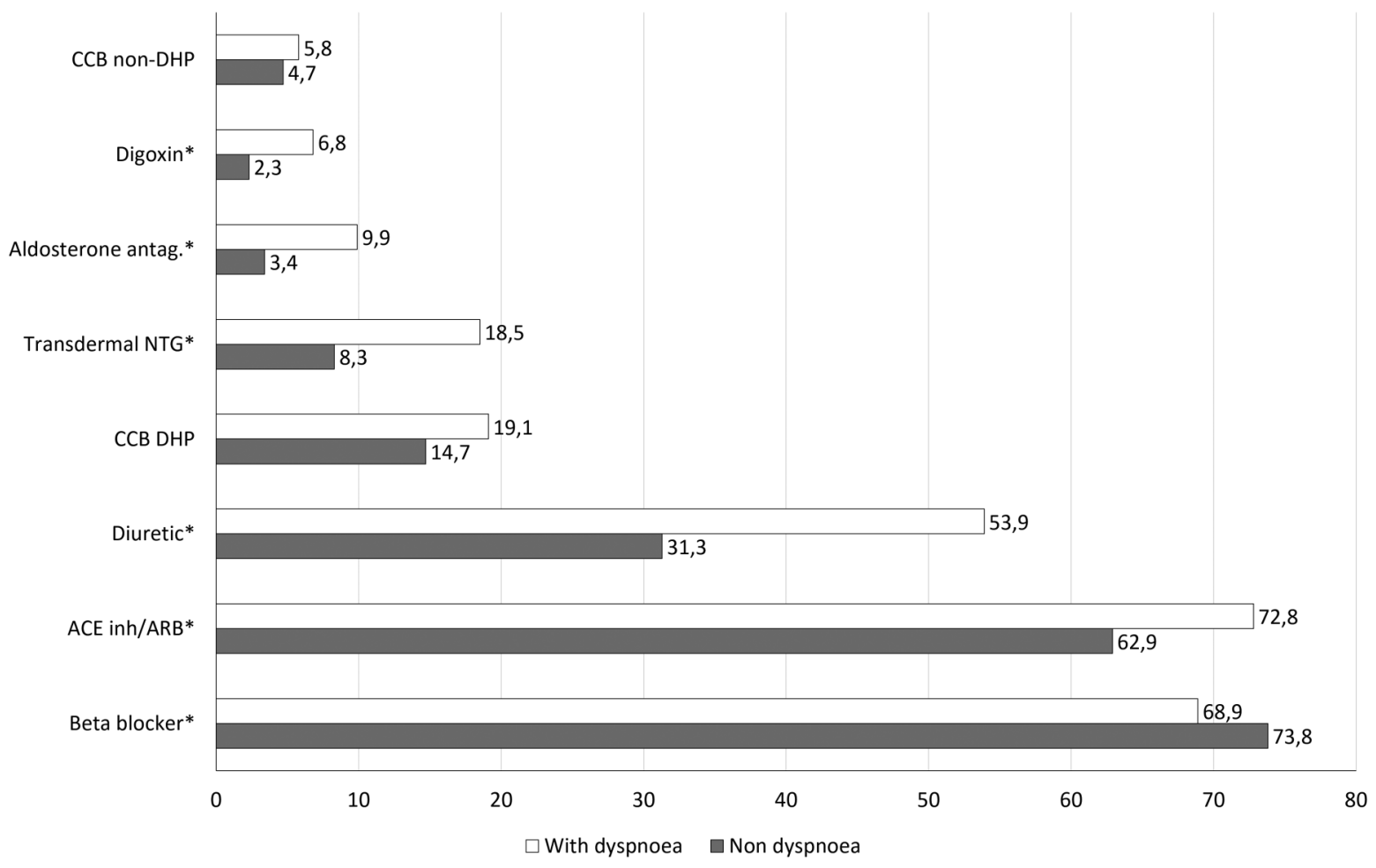

Figure 4 Treatment indication according to the presence of dyspnoea (functional class II-IV). *Differences in prevalence $(p<0.05)$. ARB, angiotensin II receptor blocker; DHP/Non-DHP CCB, dihydropyridine/non-dihydropyridine calcium channel blockers; NTG, nitroglycerine. 


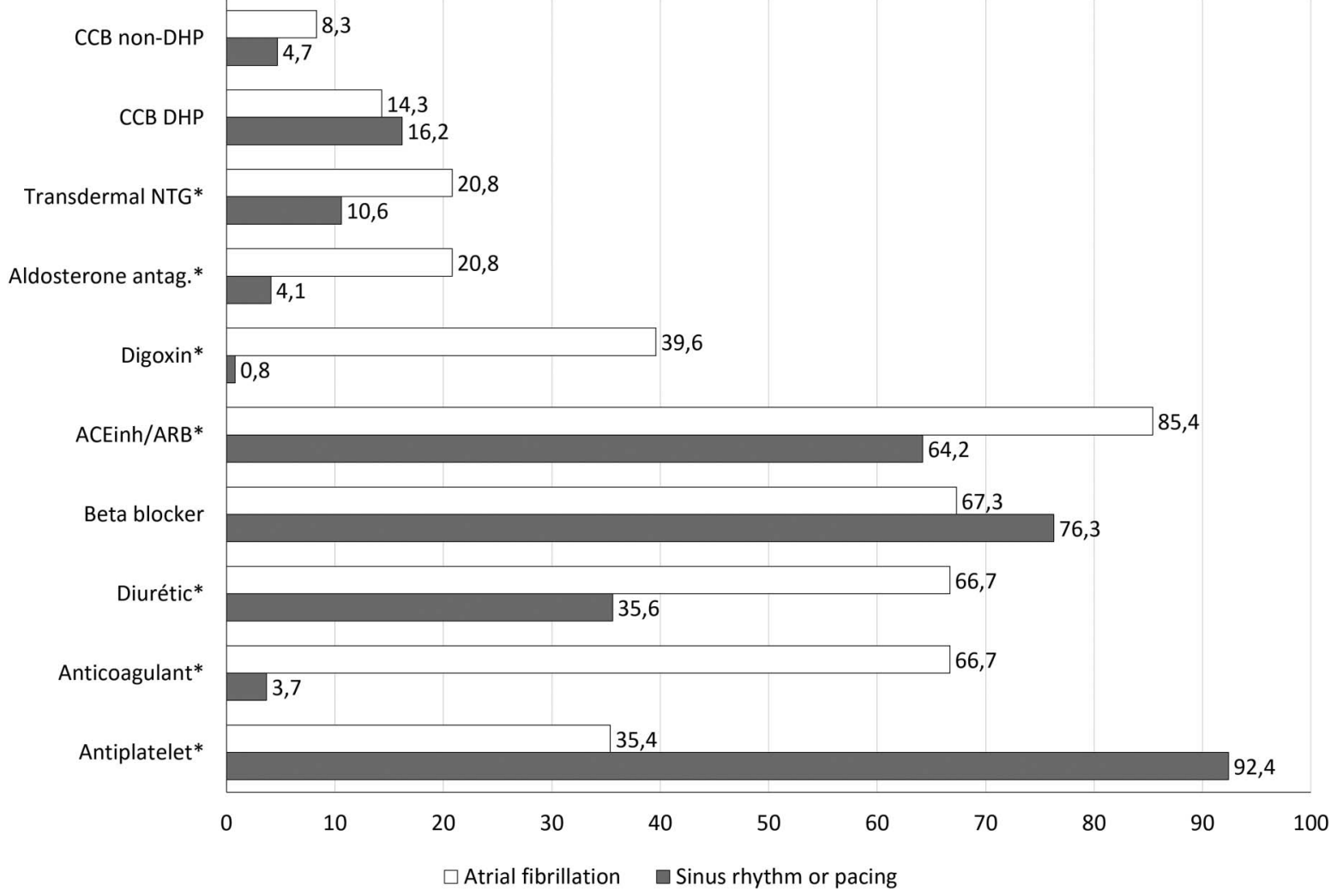

Figure 5 Treatment indication according to the presence of atrial fibrillation. *Prevalence differences $(p<0.05)$. ARB, angiotensin II receptor blocker; DHP/Non-DHP CCB, dihydropyridine/non-dihydropyridine calcium channel blockers; NTG, nitroglycerine.

Dyspnoea (functional classification II-IV) was present in a high proportion of cases $(29.3 \%)$, higher than that reported in the CLARIFY study ${ }^{8}(7 \%)$ for both the Spanish and European data. This difference may be partially explained by that study's strict clinical stability criteria. We also emphasise the low prescription of $\beta$-blockers in these patients.

Nearly $67 \%$ of those with atrial fibrillation were on anticoagulants, which represents a low proportion of patients since the vast majority of them had a score $\geq 2$ on the $\mathrm{CHA}_{2} \mathrm{DS}_{2}-\mathrm{VaSc}$ scale. ${ }^{20}$ Other Spanish studies from other areas obtained higher figures $\left(84.1 \%,{ }^{21}\right.$ $74.3 \%^{22}$ ), but among those for whom anticoagulants were indicated, ours was between the $57 \%$ from the Val-FAAP study ${ }^{23}$ and the $76.5 \%$ from the AFABE study. ${ }^{24}$ Other commonly prescribed drugs in patients with atrial fibrillation were ACE inhibitors/ARBs, diuretics and aldosterone blockers, due to possible correlation with heart failure, since they experienced dyspnoea with a higher frequency (49\% per $27.7 \%, \mathrm{p}=0.002)$.

Table 3 Multivariate analysis of the factors associated with a lack of control over at least three of the following risk factors: LDL cholesterol $<70 \mathrm{mg} / \mathrm{dL}$, blood pressure $<140 / 90$ (140/85 in patients with diabetes), heart rate $>49 \mathrm{bpm}$ and $<60 \mathrm{bpm}$, and fasting plasma glucose $<126 \mathrm{mg} / \mathrm{dL}$

\begin{tabular}{lllr}
\hline Independent variables & OR & $95 \%$ Cl & Significance level \\
\hline Age (years) & 1.015 & 1.002 to 1.031 & 0.069 \\
History of diabetes mellitus & 2.343 & 1.522 to 3.785 & $<0.001$ \\
Estimated glomerular filtration rate $<60 \mathrm{~mL} / \mathrm{min}$ & 1.834 & 1.041 to 3.575 & 0.046 \\
Obesity $(\mathrm{BMI} \geq 30)$ & 1.395 & 1.031 to 2.088 & 0.081 \\
Statins & 0.594 & 0.294 to 1.024 & 0.093 \\
$\beta$-blockers & 0.673 & 0.409 to 1.028 & 0.082 \\
\hline
\end{tabular}

$\mathrm{OR}, \mathrm{Cl}$ calculated by resampling 3000 repetitions. Hosmer-Lemeshow test: $\chi^{2} 10.862, \mathrm{p}=0.210$. Harrel's $\mathrm{C}$ discrimination index: 0.663 (95\% $\mathrm{Cl} 0.617$ to 0.709$), \mathrm{p}<0.001$.

Variables included in the model: age, sex, obesity (BMI $\geq 30$ ), abdominal obesity (waist $>102 \mathrm{~cm}$ in men, $>88 \mathrm{~cm}$ in women), history of diabetes, history of chronic kidney disease, estimated glomerular filtration rate $<60 \mathrm{~mL} / \mathrm{min}$, albumin/creatinine in morning urine $\geq 30 \mathrm{~g} / \mathrm{mg}$, percutaneous coronary intervention, drug treatments: antiplatelets, anticoagulants, $\beta$-blockers, statins.

BMI, body mass index; LDL-C, low-density lipoprotein. 


\section{Optimal medical therapy}

The OMT has been shown to significantly reduce mortality after revascularisation. ${ }^{25}$ The coverage in that study ${ }^{25}$ between $36 \%$ and $40 \%$, was similar to ours, $41.9 \%$. These patients experienced better heart rate and LDL-C control. We believe more effort is needed to bring this treatment option to as many patients as possible, since we are aware that sociodemographic and clinical factors make it difficult to do so for all. ${ }^{26}$

\section{Factors that limit risk factor control}

Variables that were independently correlated with worse control were a previous history of diabetes and a decreased glomerular filtration rate. It has been reported that diabetes makes control more difficult. ${ }^{26}$ Our novel contribution is that a reduced glomerular filtration rate also makes it harder; as such we believe early identification using the formulas recommended for that purpose $^{14}$ is a priority in these patients. Being female, which presented worse control in several risk factors, was not an independent variable, nor was age. The lack of correlation between OMT and risk factor control led us to consider that the doses of the medications were not potent enough or there was a lack of adherence to medications. This latter issue has been quantified by authors in $40 \%$ of cases. ${ }^{27}$ We believe that prescribing a medication to control a risk factor is not enough, and that we should go beyond and titrate to achieve recommended doses and to encourage patients to effectively use the medications. In our study, the prescription of $\beta$-blockers and statins was associated with a $25-50 \%$ increased of patients with good control of heart rate and cholesterol levels. However, blood pressure and glucose levels did not show an association with the prescription of medication to control both objectives.

\section{Limitations}

Within the limitations, we emphasise the participation rate, which may have conditioned the results obtained, since the non-participants in the person-to-person survey were older, with fewer revascularisation interventions (percutaneous cornonary interventions) and more comorbidity. The reasons have already been explained, being primarily transportation difficulties, both for sociodemographic and clinical-functional reasons. Among the main studies we made comparisons with, EUROASPIRE IV had a similar response rate $(48.7 \%)^{2}$ and in CLARIFY, ${ }^{8}$ the patients were recruited exclusively from cardiology departments, with those being monitored by other specialties not being represented. Other limitations were not having access to glycated haemoglobin to better assess metabolic control in patients with diabetes, imaging studies to understand heart function in patients with dyspnoea and that the angina diagnosis was exclusively clinical.

\section{New studies and intervention measures}

We consider that further efforts are needed to reduce the residual risk in patients after the occurrence of an
AMI. Several interventions should be taken into consideration. First, promoting the knowledge in primary care physicians about optimal doses and benefits of following recommendations regarding guideline-recommended medications, for overcoming the therapeutic inertia. Second, to simplify the therapeutic recommendations, promoting the use of poly-pills to increase the adherence and reduce costs. ${ }^{28}$ Third, to promote programmes of cardiac rehabilitation that have been demonstrated to increase the rate of good control of risk factors ${ }^{26}$ and improve outcome. ${ }^{29}$ Finally, patients should take more responsibility in managing their disease, with the aim of changing unhealthy lifestyle habits and improving treatment adherence. ${ }^{30}$ New initiatives are emerging that promote integrated action by all possible stakeholders to achieve these changes, ${ }^{31}$ including the use of health apps for mobile telephones. ${ }^{32}$

\section{CONCLUSIONS}

We conclude that patients with a history of 6 years of AMI from a regional hospital present large deficiencies concerning their risk factor control and treatment coverage, but these findings are similar to those of other Spanish and European registries. The worst controlled risk factors were LDL-C, heart rate and blood pressure. The presence of diabetes and a reduced glomerular filtration rate might be related to worse risk factor control. The proportion of patients with angina and/or dyspnoea was higher compared to that of other studies.

\section{Author affiliations}

${ }^{1}$ Primary Care Unit "Villanueva Norte", Programme of Investigation in Cardiovascular Diseases (PERICLES). GRIMEX Group, Villanueva de la Serena, Badajoz, Spain

${ }^{2}$ Primary Care Unit "Urbano I", Programme of Investigation in Cardiovascular Diseases (PERICLES). GRIMEX Group. Mérida, Badajoz, Spain

${ }^{3}$ Cardiac Hemodynamic Unit, Cardiology Department, Programme of Investigation in Cardiovascular Diseases (PERICLES). GRIMEX Group, "Santa Lucia" University Hospital, Cartagena, Murcia, Spain

${ }^{4}$ Cardiology Department, Don Benito-Villanueva de la Serena Hospital, Don Benito, Badajoz, Spain

${ }^{5}$ Centro Nacional de Investigaciones Cardiovasculares (CNIC), Madrid, Spain ${ }^{6}$ Cardiology Department, Monteprincipe University Hospital (HM Hospitales), Boadilla del Monte, Madrid, Spain

${ }^{7}$ Cardiology Department, Programme of Investigation in Cardiovascular Diseases (PERICLES). GRIMEX Group, Don Benito-Villanueva de la Serena Hospital, Don Benito, Badajoz, Spain

Acknowledgements The authors wish to thank the personnel at Ferrer Group for the translation of the manuscript.

Contributors FJF-R wrote the manuscript and performed the statistica analysis. DF-B participated in the design of the study and in the data collection. LLM participated in the data collection. LC-S participated in the manuscript writing and statistical analysis. The other authors participated in the critical appraisal of the manuscript. All the authors read and approved the final manuscript.

Funding Grants from Health Institute Carlos III, Ministry of Health, Government of Spain: Project $n^{\circ}$ Exp: PI 10/02153 and Emerging Group $n^{\circ}$ Exp: GEMER 07/046.

Competing interests None declared.

Patient consent Obtained. 
Ethics approval Infanta Cristina Hospital Committee.

Provenance and peer review Not commissioned; externally peer reviewed.

Open Access This is an Open Access article distributed in accordance with the Creative Commons Attribution Non Commercial (CC BY-NC 4.0) license, which permits others to distribute, remix, adapt, build upon this work noncommercially, and license their derivative works on different terms, provided the original work is properly cited and the use is non-commercial. See: http:// creativecommons.org/licenses/by-nc/4.0/

\section{REFERENCES}

1. Montalescot G, Sechtem U, Achenbach S, et al. 2013 ESC guidelines on the management of stable coronary artery disease: the task force on the management of stable coronary artery disease of the European Society of Cardiology. Eur Heart $J$ 2013;34:2949-3003.

2. Kotseva K, Wood D, De Bacquer D, et al. EUROASPIRE IV: a European Society of Cardiology survey on the life style, risk factor and therapeutic management of coronary patients from 24 European countries. Eur J Prev Cardiol Published Online First: 16 Feb 2015. doi:10.1177/2047487315569401

3. Arós $\mathrm{F}$, Cuñat $\mathrm{J}$, Loma-Osorio $\mathrm{A}$, et al. Management of myocardial infarction in Spain in the year 2000. The PRIAMHO II study. Rev Esp Cardiol 2003;56:1165-73.

4. Bueno H, Bardají A, Fernández-Ortiz A, et al. Management of non-ST-segment-elevation acute coronary síndromes in Spain. The DESCARTES (Descripción del Estado de los Síndromes Coronarios Agudos en un Registro Temporal ESpañol) study. Rev Esp Cardiol 2005;58:244-52.

5. Ferreira-González I, Permanyer-Miralda G, Marrugat $\mathrm{J}$, et al. MASCARA (Manejo del Síndrome Coronario Agudo. Registro Actualizado) study. General findings. Rev Esp Cardiol 2008:61:803-16.

6. Barrabés JA, Bardaji A, Jiménez-Candil J, et al. Prognosis and management of acute coronary syndrome in Spain in 2012: the DIOCLES study. Rev Esp Cardiol 2015;68:98-106.

7. Fernández-Bergés D, Félix-Redondo FJ, Consuegra-Sánchez L, et al. Myocardial infarction in older than 75 years: an increasing population. CASTUO study. Rev Clín Esp 2015;215:195-203.

8. Zamorano JL, García-Moll X, Ferraric Y, et al. Demographic and clinical characteristics of patients with stable coronary artery disease: results from the CLARIFY registry in Spain. Rev Esp Cardiol (Engl Ed) 2014;67:538-44.

9. Reina A, Colmenero M, Aguayo de Hoyos E, et al. Gender differences in management and outcome of patients with acute myocardial infarction. Int J Cardiol 2007;116:389-95.

10. Bardají $\mathrm{A}$, Bueno $\mathrm{H}$, Fernández-Ortiz $\mathrm{A}$, et al. Type of treatment and short-term outcome in elderly patients with acute myocardial infarction admitted to hospitals with a primary coronary angioplasty facility. The TRIANA (TRatamiento del Infarto Agudo de miocardio eN Ancianos) Registry. Rev Esp Cardiol 2005;58:351-8.

11. Alexander KP, Newby LK, Cannon CP, et al. Acute coronary care in the elderly, part I. Non-ST-segment elevation acute coronary syndrome. A scientific statement for health care professionals from the American Heart Association council on clinical Cardiology. Circulation 2007;115:2549-69.

12. Bardaji $A$, Cediel $G$. The challenge of caring for myocardial infarction in the elderly. Rev Clin Esp 2015;215:217-18.

13. Degano IR, Elosua R, Marrugat J. Epidemiology of acute coronary syndrome in Spain: estimation of the number of cases and trends from 2005 to 2049. Rev Esp Cardiol (Engl Ed) 2013;66:472-81.

14. Martinez-Castelao A, Gorriz JL, Bover J, et al. Consensus document for the detection and management of chronic kidney disease. Nefrologia 2014;34:243-62.
15. Pérez de Isla L, Saltijeral A, Vitale G, et al. Prevalence of inappropriate LDL cholesterol levels in patients with coronary disease and/or type 2 diabetes. Rev Clin Esp 2012;212:475-81.

16. Yusuf $S$, Islam $S$, Chow CK, et al. Use of secondary prevention drugs for cardiovascular disease in the community in high-income, middle-income and low-income countries (the PURE study): a prospective epidemiological survey. Lancet 2011;378:1231-43.

17. Diaz A, Bourassa MG, Guertin MC, et al. Long-term prognostic value of resting heart rate in patients with suspected or proven coronary artery disease. Eur Heart J 2005;26:967-74.

18. Kotseva K, Wood D, De Backer G, et al. Cardiovascular prevention guidelines in daily practice: a comparison of EUROASPIRE I, II, and III survey in eight European countries. Lancet 2009;373:929-40.

19. Hayward RA, Reaven PD, Wiitala WL, et al. Follow-up of glycemic control and cardiovascular outcomes in type 2 diabetes. $N$ Engl $J$ Med 2015;372:2197-206

20. Fernandez-Berges D, Felix-Redondo FJ, Consuegra-Sanchez L, et al. Are the $\mathrm{CHADS}_{2}$ y $\mathrm{CHA}_{2} \mathrm{DS}_{2}$-Vasc scales useful instruments to initiate anticoagulant medication? Rev Clin Esp 2012;212: 418-19.

21. Lobos-Bejarano JM, del Castillo-Rodríguez JC, Mena-González A, et al. Patients' characteristics and clinical management of atrial fibrillation in primary healthcare in Spain. FIATE study. Med Clin 2013;141:279-86.

22. Baena-Diez JM, Grau M, Forés R, et al. Prevalence of atrial fibrillation and its associated factors in Spain: an analysis of 6 population-based studies. DARIOS study. Rev Clin Esp 2014;214:505-12.

23. Barrios V, Calderón A, Escobar C, et al. Patients with atrial fibrillation in a primary care setting: Val-FAAP study. Rev Esp Cardiol (Engl Ed) 2012;65:47-53.

24. Clua-Espuny JL, Lechuga-Durán I, Bosch-Princep R, et al. Prevalence of undiagnosed atrial fibrillation and of that not being treated with anticoagulant drugs: the AFABE study. Rev Esp Cardiol (Engl Ed) 2013;66:545-52.

25. Iqbal J, Zhang Y-J, Holmes DR, et al. Optimal medical therapy improves clinical outcomes in patients undergoing revascularization with percutaneous coronary intervention or coronary artery bypass grafting. Circulation 2015;131:1269-77.

26. Cooney MT, Kotseva K, Dudina A, et al. Determinants of risk factor control in subjects with coronary heart disease: a report from the EUROASPIRE III investigators. Eur J Prev Cardiol 2013;20: 686-91.

27. Chowdhury R, Khan $\mathrm{H}$, Heydon $\mathrm{E}$, et al. Adherence to cardiovascular therapy: a meta-analysis of prevalence and clinical consequences. Eur Heart J 2013;34:2940-8.

28. Castellano JM, Sanz G, Peñalvo JL, et al. A polypill strategy to improve adherence: results from the FOCUS Project. J Am Coll Cardiol 2014;64:2071-82.

29. Anderson L, Taylor RS. Cardiac rehabilitation for people with heart disease: an overview of Cochrane systematic reviews. Cochrane Database Syst Rev 2014;12:CD011273.

30. Mathews R, Wang TY, Honeycutt E, et al. Persistence with secondary prevention medications after acute myocardial infarction: insights from the TRASLATE-ACS study. Am Heart $J$ 2015;170:62-9.

31. Arena R, Guazzi M, Lianov L, et al. Healthy lifestyle e interventions to combat non-communicable disease -a novel nonhierarchical connectivity model for key stakeholders: a policy statement from the American Heart Association, European Society of Cardiology, European Association for Cardiovascular Prevention and Rehabilitation and American College of Preventive Medicine. Eur Heart J 2015;36:2097-109.

32. Burke LE, Ma J, Azar KMJ, et al. Current science on consumer use of mobile health for cardiovascular prevention: a scientific statement from the American Heart Association. Circulation 2015;132:1157-213. 